\title{
Assessment Level of Severity of Environmental Disturbance Caused by Aquaculture Activities Using Abundance-Biomass Curves of Macrobenthic Assemblages
}

\author{
Sapto P. Putro, Widowati, and Suhartana
}

\begin{abstract}
Abundance-Biomass comparison (ABC) was applied to assess the level of environmental disturbance by the changes in the pattern of abundance and biomass of macrobenthic assemblages taken from various types of sediments. In the most sedimentary habitats, polychaetes usually dominate the structure and considered the most tolerant to stress associated with organic loading and low oxygen levels, thus effective as environmental indicator using $\mathrm{ABC}$ curve. The aim the study is to assess the environmental changes caused by Aquaculture activities using ABC curve of polychaetes assemblages as presented using the Shannon-Wiener $\left(H^{\prime}\right)$ index at the studied areas. The results showed that approach to multivariate and graphical methods, especially using ABC curves can sensitively detect any environmental change, particularly changes in polychaetesassemblages, water quality and sediment over time.
\end{abstract}

Index Terms-Polychaete assemblages, $\mathrm{ABC}$ curve, environmental disturbance, organic enrichment, sustainable aquaculture, biomonitoring.

\section{INTRODUCTION}

Marine benthic organisms have a variable sensitivity to disturbance. Therefore, an increasing level of disturbance may either decrease or increase diversity or it may even remain the same [1], a condition that may not be easily detected by univariate statistical techniques [2]. In order to assess the rates and degree of environmental disturbance, multivariate techniques have been developed and widely used, as they are considered more sensitive for detecting community changes than univariate techniques [3].

One group of macrobenthic community that occupies almost all benthic marine and estuarine sedimentary habitats and contributes a major part of the total macrofaunal diversity is polychaetes [4], [5]. This is mainly because polychaetes are the marine invertebrates most tolerant to stress associated with organic loading and low oxygen levels. Their high numerical abundance in polluted areas can thus be used as environmental indicators [6]-[8]. Polychaete worms play an

Manuscript received March 10, 2014, revised June 20, 2014. This work was financially supported by 'Competence Grant/Hibah Kompetensi" The $3^{\text {rd }}$ Year, 2014 under Ditlitabmas Program-Directorate General of Higher Education (DIKTI).

Sapto P. Putrois with the Department of Biology, Faculty of Sciences and Mathematics, Diponegoro University, Jl. Prof. Soedarto, SH, Tembalang Campus, Semarang 50275, Indonesia (e-mail: saptoputro@ undip.ac.id).

Widowati is with the Department of Mathematics, Faculty of Sciences and Mathematics, Diponegoro University, Jl. Prof. Soedarto, SH, Tembalang Campus, Semarang 50275, Indonesia (e-mail: widowatimath@ undip.ac.id).

Suhartana is with the Department of Chemistry, Faculty of Sciences and Mathematics, Diponegoro University, Jl. Prof. Soedarto, SH, Tembalang Campus, Semarang 50275, Indonesia (e-mail: suhartanagi_putra@yahoo.com). important role in recycling, reworking, and bioturbation of sediments through burrowing and feeding activities, thus enhancing sedimentary processes [9], [10].

Graphical methods, such as abundance biomass comparison $(\mathrm{ABC})$, have been introduced and applied to assess the level of environmental disturbance [1], [3]. The method has been illustrated initially in a graphical model by [11] in assessing the changes in numbers of species, abundance, and biomass (SAB) in response to organic enrichment applicable to all habitats where organic enrichment occurs. The changes in the pattern of abundance and biomass of macrobenthic assemblages may be used as an indicator of community disturbance. The levels of disturbance can be characterised by a shift in the proportions of different phyla and in relative distribution of abundance and biomass of species with increasing levels of disturbance. For instance, sediments contaminated by chemical compounds may reduce trophic complexity, and lead to benthic assemblages dominated by opportunistic species.

In theory, the macrobenthic assemblages under stable condition or low level of disturbance are competitively dominated by conservative species, which have a so-called "K-selected" life history attributed by large-body size and long life-span, dominating in biomass but not in numbers. In a disturbed areas, macrobenthic assemblages are dominated by "r-selected" organisms or opportunistic species characterized by small-body size and short life-span, dominating in numbers but not in biomass, have high reproductive potential and early maturation [12]. In such a situation, conservative species are less favored so that the opposite situation may occur. Depending on the level of disturbance, the biomass curve may lie above the abundance curve (for undisturbed areas) or under the abundance curve ( for heavily/grossly disturbed areas) or they may be closely coincident for their entire length or may cross each other one or more times (for moderately disturbed areas) [2], [13]. The data were analysed and illustrated graphically to generate ABC curve using Pirmer 5.1.2 software [14].

\section{MATERIALS AND METHODS}

\section{A. Sampling Procedures}

Samples of macrobenthic assemblages were taken from sediments using HAPS corer under southern blue-fin tuna farms in southern Spencer Gulf, South Australia, representing a temperate region as Location I, and under fish impoundment at coastal region of Demak District, Central Java, Indonesia, representing tropical regions as Location II Each location has a reference site, which is a least $1 \mathrm{~km}$ away 
from farming site. Samples were taken from three stations for each location with four replicates. Physico-chemical parameters of water were measured in situ.

\section{B. Laboratory Procedures}

Samples were then preserved with $4 \%$ formalin solution. Laboratory procedures include sieving, sorting, counting and identifying the fauna that has been preserved in $70 \%$ ethanol. Ash free dry weight (AFDW) analysis was carried out for biomass measurement. The biotic datas recorded for further analysis were abundance and biomass of macrobenthic assemblages animals.

\section{Data Analyses}

The changes in the dominance pattern of macrobenthic assemblages based on both abundance and biomass were assessed using the Abundance/Biomass Comparison (ABC) method [1], [3]. The ABC method was used to determine a shift in the proportions of different phyla and in relative distributions of abundance and biomass among taxa between reference sites and fish farming sites, and over time. The ' $W$ ' plotted in graphs is Clarke's W statistic describing the degree and direction of separation of the curves [1], [3] and is calculated as shown in a formula (1):

$$
W=\sum_{i=1}^{S} \frac{\left(B_{i}-A_{i}\right)}{[50(S-1)]}
$$

where $S$ is number of species, $A_{i}$ is abundance of species $i$, and $B_{i}$ is biomass of species $i$. The value of $W$ is in the range between -1 and +1 , where $W \rightarrow+1$ for even abundances across species but biomass is dominated by a single species (undisturbed), and $W \rightarrow-1$ in the converse case (severely disturbed) [1], [3].

\section{RESUlTS AND DisCUSSION}

At Location I, the results of the $\mathrm{ABC}$ analyses from reference sites and fish farming sites of the temperate region for the first sampling time and the last sampling times in a year period are shown in Fig. 1. At the beginning of the study, the biomass curve lies above the abundance curve for its entire length at the reference sites, indicating an undisturbed area. Conversely, the abundance curve at the fish farming sites lies above the biomass curve from the starting point to the middle of the curves where they cross, indicating a moderately disturbed area [11], [12].

At the reference site for beginning of the sampling time, the abundance curve lies below the biomass curve, indicating undisturbed areas. However, by the end of sampling time, the curve of biomass intercepts the abundance curve from the starting point to the middle where they cross to the end of the curve, indicating a moderate pollution. At the fish farming sites, the biomass curve intercept the abundance curve both from the beginning of the sampling time throughout the end of the study, indicating moderately disturbed areas by [11] criterion. These results imply that a constant downsteamflux of particulate organic matter produced by fish farming activities may be generated in such conditions.

The moderate level of disturbance at reference sites by the end of the study time at Location I may be because of the extension of impacts of farming to the reference sites, because the current velocity in the study site is relatively strong. Thus, hydrodynamic conditions with a relatively strong current velocity may affect the dispersion of particulate matter, and cause an extended zone of impact. These results are in accordance with those of [15] in the Gulf of Castellammare, Meditteranean, where fish farm facilities generated an organic enrichment of the water column extended at least $1000 \mathrm{~m}$ downstream from the cages. The mean water current velocities throughout the year in the Gulf of Castellammare are about $10-12 \mathrm{~cm} \mathrm{~s}^{-1}$, which is similar to the $8-10 \mathrm{~cm} \mathrm{~s}^{-1}$ currents in the southern Spencer Gulf. Conversely, the fish farming farm sites have been moderately polluted throughout the sampling period, indicated by the abundance curve that intercept the biomass curve, both in the first and the end of sampling time.

Given that the environmental variables and benthic assemblages generally showed differences between the two sites, and diversity and evenness at reference sites were considerably higher than at fish farming sites, the abundance of dominant taxa is more likely to be the main factor affecting the similar level of disturbance at both sites. The proportions of dominant species of polychaetesoccurred at both sites. Most of them are considered as opportunistic species, which have small-body size, and grow rapidly in response to a disturbance, especially organic enrichment [1], [5]. [16] found that, there was evidence of macrobenthic recovery fifteen months after fallowing. However, opportunistic species were still dominating, suggesting that the areas were moderately to slightly disturbed at the end of the study. Response of opportunistic species may be due to the excess of organic matter in the sediment caused by fish farming.
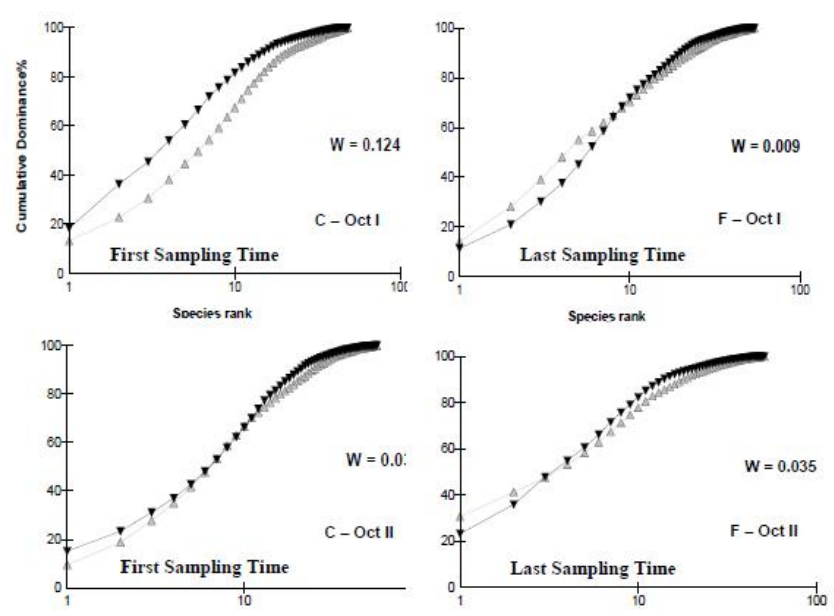

Fig. 1. The $\mathrm{ABC}$ curves at reference and fish farming sites plotted, comparing the first sampling period and the end of sampling time over a full year assessment at the temperate region. The curves were projected based on data transformation $\log (X+1)$ of abundance $(\Delta)$ and biomass $(\boldsymbol{\nabla})$ of macrobenthic assemblages.

Most opportunistic taxa are categorized as sub-surface deposit feeders (SSDF), thus the more number of SSDF may indicate the higher level of disturbance [17], [18] recorded a decreased species richness under salmon farms, characterized by the dominance of small body sized macrobenthic fauna, with increasing proximity to the farm sites. Similar patterns of macrobenthic succession under three different fish farms were reported [19] In this study, statistical analyses showed that there were no significant differences in the abundance of 
the dominant taxa between reference and fish farming sites at the end of sampling period, leading to similar patterns of the $\mathrm{ABC}$ curves between reference and fish farming farm sites.

Based on the ABC curves and $\mathrm{W}$ statistic for each site and time, some sites are categorized as moderately disturbed, some others as undisturbed. The sites categorized as moderately disturbed for each sampling time are shown in Table I.

TABLE I: THE SELECTED FARMING AND REFERENCE SITES CLASSIFIED AS MODERATELY DISTURBED FOR EACH SAMPLING TIME

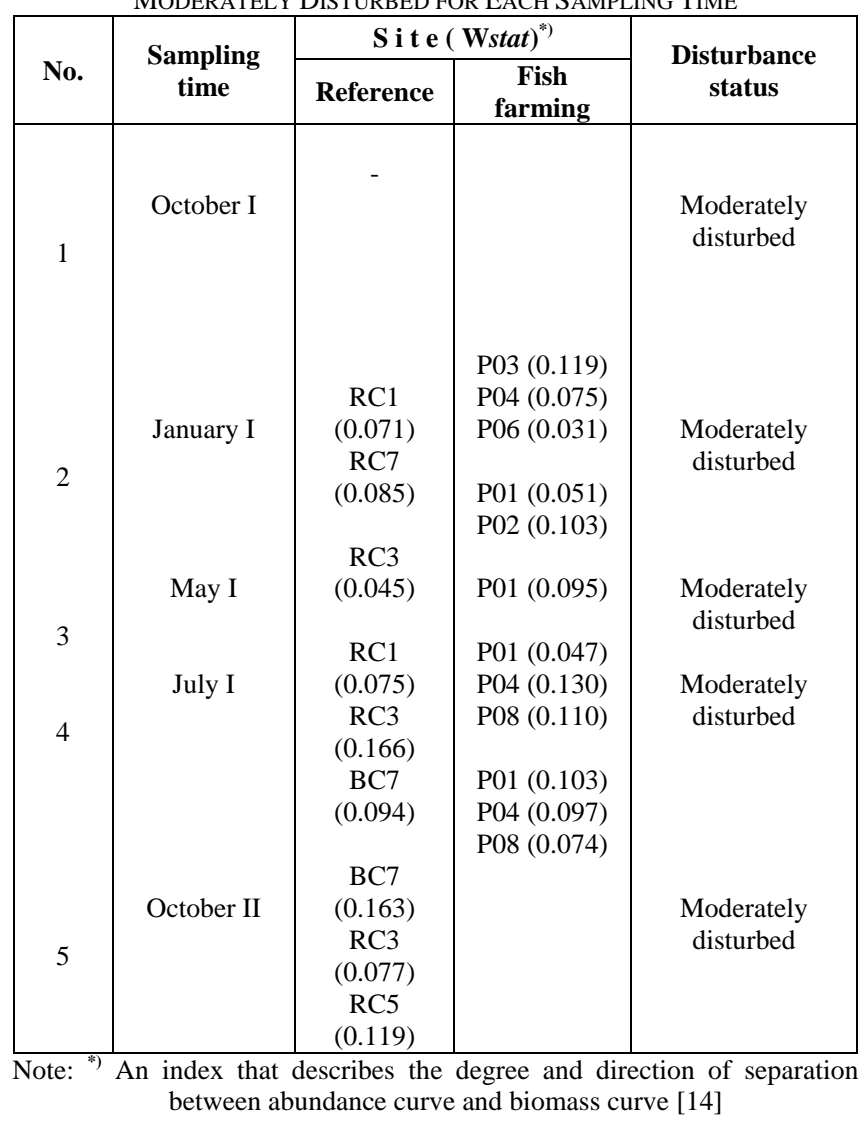

At Location II, Based on the criteria proposed by [11], all the sampling stations on the sampling time I (July) is categorized as a disturbed/ polluted area, except station TC01SD1B (mixed ponds; inlet) and station TC02SD1B (mixed pond; outlet). This area is used as mixtures to obtain the flow of water directly from the River Ronggolawe. The river is still affected directly by the tidal wave, so the quality of water used is still relatively good.

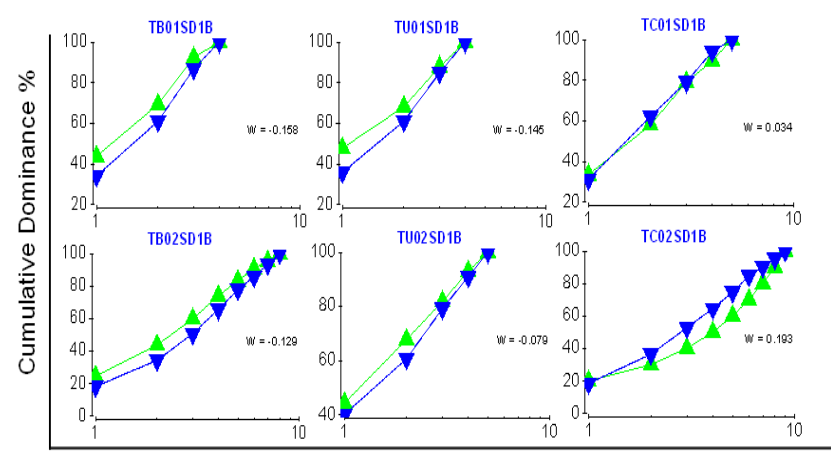

Snecies Rank

Fig. 2. Abundance Biomass Curves Curve $(A B C)$ is projected based on data transformation $\log (X+1)$ of abundance $(\Delta)$ and biomass $(\nabla)$ macrobenthic assemblages in the first sampling time at the tropical region.
While the input water for shrimp and milkfish ponds are from mixed pond, so that water quality has been affected by the activity of farming in the mixed pond. Unlike the sampling time I, the curve shown for

Meanwhile, results from the analysis of abundance and biomass of macrobenthic assemblages projected as $\mathrm{ABC}$ curve of the tropical region showed variability between stations (Fig. 2 and Fig. 3).

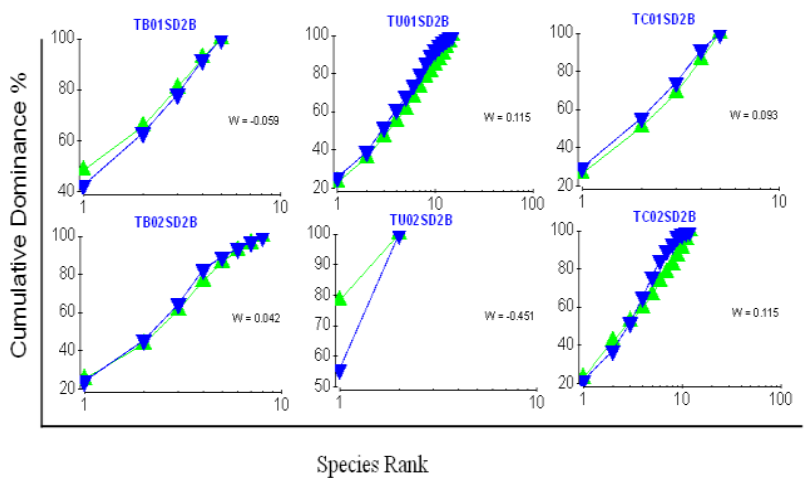

Fig. 3. Abundance Biomass Curves Curve $(A B C)$ is projected based on data transformation $\log (X+1)$ of abundance $(\Delta)$ and biomass $(\boldsymbol{\nabla})$ of macrobenthic assemblages in the second sampling time.

Based on the criteria proposed by 2, all the sampling stations on the sampling time I (July) is categorized as a disturbed/ polluted area, except station TC01SD1B (mixed ponds; inlet) and station TC02SD1B (mixed pond; outlet), as shown in Fig. 3. This area is used as mixtures to obtain the flow of water directly from the River Ronggolawe. The river is still affected directly by the tidal wave, so the quality of water used is still relatively good. While the input water for shrimp and milkfish ponds are from mixed pond, so that water quality has been affected by the activity of farming in the mixed pond.

Unlike the sampling time I, the curve shown for each station on the sampling II (October) is categorised as undisturbed areas (unpolluted), except station TB01SD2B (milkfish ponds; outlet) and station TU02SD2B (shrimp ponds; outlet) (Fig. 3). This indicates that the two stations above have been disturbed in October's samples. Based on the results of interviews with the owner/manager of shrimp farms (personal communication), the condition of shrimp pond a week before sampling II (early October) has been environmentally disturbed, resulting in most of the stocked shrimp died (more than $70 \%$ of total population). It is not yet known the cause of the disturbance, but is expected related to the quality of feed and less aeration in the pond. Poor feed quality will reduce or even eliminate appetite of the animals. This can cause the accumulation of feed into body water and partially decomposed into sediment. The presence of high organic matter can trigger the growth of toxic microalgae and pathogenic bacteria in the waters, so it can result in lowered resistance of the cultured animals against the diseases.

Given that the environmental variables and benthic assemblages generally showed differences between the two sites, and diversity and evenness at reference sites were considerably higher than at fish farming sites, the abundance of dominant taxa is more likely to be the main factor affecting the similar level of disturbance at both sites. The proportions of dominant taxa (which are all polychaetes) at both sites are the highest compared to the other macrobenthic taxa, 
suggesting that the contribution of these taxa to the level of disturbance, using ABC curves, was substantial. Most of them are considered as opportunistic species, which have small-body size, and grow rapidly in response to a disturbance, especially organic enrichment [1], [11], [12]. In this study, statistical analyses showed that there were no significant differences in the abundance of the dominant taxa between reference and fish farming sites, except for Lumbrineridae. These results lead to similar patterns of the $\mathrm{ABC}$ curves between reference and fish farming sites, especially biomass curves.

Despite the successful using of the ABC method, inconsistency has also been reported [2]. The ABC method is strongly influenced by the presence of small numbers of large-size species [20] and over-influenced by the single most dominant species [2]; therefore, the absence or presence of single or several dominant species can cause inappropriate classification of the status of disturbance using the $\mathrm{ABC}$ method.

\section{CONCLUSION}

Macrobenthic assemblages animals are very sensitive to changes in the environment, particularly water quality and sediment. In general, the disturbance or physical-chemical changes in the environment will respond to changes in the composition and abundance the animals. Approach to multivariate and graphical methods, especially using ABC curves can sensitively detect any environmental change, particularly changes in macrobenthic assemblages, water quality and sediment over time both temperate and tropical regions. The ABC method is strongly influenced by the presence of small numbers of large-size species and over-influenced by the single most dominant species that may lead to inappropriate classification of the status of disturbance using the ABC method.

\section{REFERENCES}

[1] R. M. Warwick and K. R. Clarke, "Relearning the ABC: Taxonomic changes and abundance/biomass relationships in disturbed communities," Marine Biology, vol. 118, pp. 739-744, 1994.

[2] K. R. Clarke and R. M. Warwick, "Change in marine comunities: An approach to statistical analysis and interpretation," Primer-E Playmouth, pp. 180-190, 2001.

[3] R. M. Warwick and K. R. Clarke, "Comparing the severity of disturbance: A meta-analysis of marine macrobenthic community data," Marine Ecology Progress Series, vol. 92, pp. 221-231, 1993.

[4] K. Fauchald, "The polychaete worms: Definitions and keys to the orders, families, and genera," Natural History Museum of Los Angeles County, Los Angeles, vol. 1, pp. 5-15, 1977.

[5] S. P. Putro, Environmental Quality Assessment of Fish Farming: Solutions Toward Sustainable Aquaculture, Lambert Academic Publishing, Saarbrucken, Germany, vol. 1, pp. 22-50, 2010.

[6] L. A. Levin and J. D. Gage, "Relationships between oxygen, organic matter and the diversity of bathyalmacrofauna," Deep Sea Research Part II: Topical Studies in Oceanography, vol. 45, pp. 129-163, 1998.

[7] S. P. Putro, "The development biomonitoring method used for environmental disrubance assessment under fish farms usingmacrobenthicstructure at Lake Rawapening, CentralJava," in Proc. Workshop on Lake Danau Rawapening, Hotel Ciputra Semarang, June 13, 2013.

[8] S. P. Putro, A. Sudaryono, Suhartana, and Hariyati, "Response of trophic groups of macrobenthos to organically enriched sediments: A comparative study between temperate and tropical regions," Journal of Aquatic Science and Technology, vol. 2, no. 1, pp. 15-29, 2014.

[9] P. Hutchings, "Biodiversity and functioning of polychaetes in benthic sediments," Biodiversity and Conservation, vol. 7, pp. 1133-1145, 1998.
[10] L. Levin, W. Ziebis, and G. F. Mendoza et al., "Spatial heterogeneity of macrofauna at northern California methane seeps: influence of sulfide concentration and fluid flow,"Marine Ecology Progress Series, vol. 265, pp. 123-139, 2003

[11] T. H. Pearson and R. Rosenberg, "Macrobenthic succession in relation to organic enrichment and pollution of the marine environment," Oceanography and Marine Biology Annual Review, vol. 16, pp. 229-311, 1978

[12] R. J. Diaz and R. Rosenberg, "Marine benthic hypoxia: A review of its ecological effects and the behavioural responses of benthic macrofauna," Ocean Mar. Biol. Ann. Rev., vol. 33, pp. 245-251, 1995.

[13] K. R. Clarke, P. J. Somerfield, and M. Chapman, "On resemblance measures for ecological studies, including taxonomic dissimilarities and a zero-adjusted Bray-Curtis coefficient for denuded assemblages," J. Exp. Mar. Biol. Ecol., vol. 338, pp. 179-185, 2006.

[14] K. R. Clarke and R. N. Gorley, Primer v6: User Manual/Tutorial, PRIMER-E, Plymouth, p. 190, 2006

[15] A. Modica, D. Scilipoti, R. L. Torre, and A. Manganaro, "The effect of mariculture facilities on biochemical features of suspended organic matter (southern Tyrrhenian, Mediterranean)," Estuarine, Coastal and Shelf Science, vol. 66, no. 1-2, pp. 177-184, 2006.

[16] P. M. F. Pereira, K. D. Black, D. S. McLusky, and T. D. Nickell, "Recovery of sediments after cessation of marine fish farm production," Aquaculture, vol. 235, pp. 315-330, 2004

[17] S. P. Putro, "Response of trophic groups of macrobenthic fauna to environmental disturbance caused by fish farming," Journal of Coastal Development, vol. 12, no. 3, pp. 146-159, 2009

[18] D. P. Weston, "Quantitative examination of macrobenthic community changes along an organic enrichment gradient," Marine Ecology Progress Series, vol. 61, pp. 233-244, 1990.

[19] I. Karakassis, M. Tsapakis, E. Hatziyanni, K. N. Papadopoulou, and W Plaiti, "Impact of cage farming of fish on the seabed in three Mediterranean coastal areas," ICES Journal of Marine Science, vol. 57 pp. 1462-1471, 2000.

[20] D. M. Dauer, M. W. Luckenbach, and J. Rodi, "Abundance biomass comparison (ABC method): Effects of the estuarine gradient, anoxic/hypoxic events and contaminated sediments," Marine Biology, vol. 116, pp. 507-518, 1993

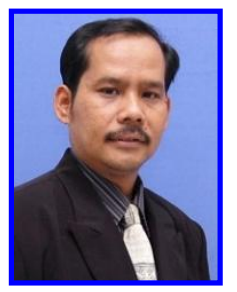

Sapto P. Putro was born in Tebing Tinggi, South Sumatra on December 26, 1966. He graduated from Flinders University, South Australia in 2006 for his $\mathrm{PhD}$ in marine ecology and aquaculture.

He spent many years studying environmental and ecological assessment of aquaculture activities, both temperate and tropical regions. He is now a senior lecturer in ecology and aquaculture at the Faculty of Sciences and Mathematics, Diponegoro University, Indonesia. His current research is focusing on the development of polyculture and integrated multi-trophic aquaculture using stratified double floating net cages integrated with rapid method of biomonitoring for sustainable aquaculture.

Dr. Putro actively involves in national and international scientific conference and membership of Indonesia Aquaculture Society (IAS) and World Aquaculture Society (WAS). Excellent paper and high quality article have been awarded during his national and international conference/publications.

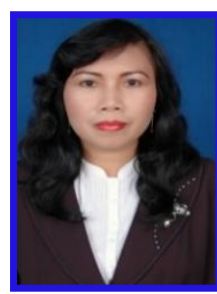

Widowati was born in Kebumen, Central Java on February 14, 1969. She finished her study for her master degree in applied mathematics at InstitutTeknologi Bandung and finish her doctoral degree at the same institution in 2005. Her research focuses on mathematical modeling and its application, such as model reduction for unstable lpv systems based on coprime factorization and singular. She is a senior lecturer at Faculty of Sciences and Mathematics, Diponegoro University, Indonesia.

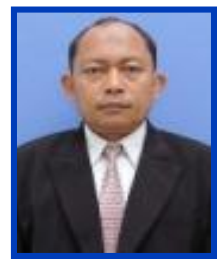

Suhartana was born in Bantul, Central Java on October 13, 1963. His master degree was gained at Gadjag Mada University in anorganic chemistry. He spent many years for doing his research on the use of anorganic/organic materials for waste water treatment. $\mathrm{He}$ is now a senior lecturer in anorganic chemistry at Faculty of Sciences and Mathematics, Diponegoro University. 